\title{
INSPEÇÃO DE ESTRUTURAS DE CONCRETO ATRAVÉS DE ENSAIOS ULTRASSÔNICOS
}

\author{
ALEXANDRE LORENZI \\ Engenheiro Civil \\ LEME/UFRGS \\ RS; Brasil \\ alexandre.lorenzi@ufrgs.br \\ LUIZ CARLOS PINTO DA SILVA FILHO \\ Engenheiro Civil \\ LEME/UFRGS \\ RS; Brasil \\ lcarlos66@gmail.com
}

\author{
LUCAS ALEXANDRE REGINATTO \\ Engenheiro Civil \\ LEME/UFRGS \\ RS; Brasil \\ lucas.reginatto@ufrgs.br
}

\author{
LUCIANI SOMENSI LORENZI \\ Engenheira Civil \\ LEME/UFRGS \\ RS; Brasil \\ luciani.lorenzi@gmail.com
}

\begin{abstract}
RESUMO
O concreto é o elemento estrutural mais utilizado no mundo e constitui como parte fundamental dos mais variados projetos de engenharia. Diante destes fatos, são necessárias ferramentas para inspeção e controle das estruturas de concreto armado. Nos dias atuais existe uma preocupação crescente sobre o estado de deterioração e segurança das estruturas de concreto armado. Os Ensaios Não Destrutivos (END) tornam-se uma estratégia de investigação bastante atraente e viável, pois permitem o monitoramento constante de estruturas sem causar danos as mesmas. Dentre os métodos de END mais utilizados o Ensaio de Velocidade de Propagação do Pulso Ultrassônico (VPU) vem sendo usado constantemente para inspeção de estruturas de concreto armado e demonstra grande potencial na investigação de estruturas. Desta forma, pode-se concluir que através da aplicação do ensaio de VPU consegue-se um controle da deterioração e qualidade das estruturas de concreto. O presente artigo evidencia como podem ser empregados os ensaios de VPU para inspeção e controle de estruturas de concreto, ilustrando uma série de estudos de caso realizados pela equipe técnica do Laboratório de Ensaios e Modelos Estruturais (LEME/UFRGS).
\end{abstract}

Palavras-chave: Deterioração, Segurança, Defeitos.

\section{ABSTRACT}

Concrete is the widely used structural element in the world and is a fundamental part of many engineering projects. Tools are required for inspection and control of reinforced concrete structures. Nowadays there is growing concern about the state of deterioration and safety of reinforced concrete structures. Nondestructive Testing (NDT) becomes a very attractive and viable research strategy as it allows constant structures monitoring without damage. Among the most used NDT methods the Ultrasonic Pulse Velocity (UPV) has been used constantly for inspection of reinforced concrete structures and demonstrates great potential at structures investigation. It can be concluded that thought UPV applications it is possible to control the deterioration and quality of concrete structures. This paper shows applications of UPV for inspection and control of concrete structures. The studies were developed by the LEME-UFRGS Research Group regarding their application.

Keywords: Deterioration, Safety, Defects.

\section{INTRODUÇÃO}

A utilização de END na engenharia civil vem se tornando um tema de interesse em diversos países. No caso da indústria da construção civil, porém, que utiliza vários tipos de materiais (metais, madeira, concreto, alvenaria estrutural e outros compósitos), a utilização dos END pode se tornar mais complexa, devido à necessidade de maior conhecimento acerca das propriedades e comportamento dos materiais. A Engenharia Civil é um campo no qual a utilização dos END pode se desenvolver bastante, vindo a se constituir em uma importante ferramenta para auxiliar os profissionais envolvidos no controle de qualidade do concreto. 
Para Balayssac et al. (2009), a aplicação de END no campo da Engenharia Civil é muito interessante por fornecer, de maneira rápida e eficaz, informações qualitativas a respeito do concreto, da variabilidade de suas propriedades e também parâmetros sobre a evolução do material no tempo. A aplicação de END pode-se constituir uma estratégia interessante para monitorar o estado de conservação das estruturas de concreto. Para esta finalidade deve-se levar em consideração que a propriedade de controle mais utilizada como indicativa da qualidade do concreto ainda é a resistência à compressão. Considerando que a resistência está fortemente correlacionada com a densidade do material, podem-se utilizar os END para avaliar a mesma, sem que seja necessário retirar amostras do material.

O documento TCS-17, produzido pela Agência Internacional de Energia Atômica (IAEA, 2002), aponta várias situações específicas associadas à construção civil nas quais o emprego de métodos END pode ser considerado atraente:

$\checkmark$ controle tecnológico em pré-moldados ou construções in situ;

$\checkmark$ aceitação ou rejeição, de materiais fornecidos;

$\checkmark$ esclarecimento de dúvidas a respeito da mão de obra envolvida em mistura, lançamento, compactação ou cura do concreto, transporte;

$\checkmark$ monitoramento do desenvolvimento da resistência visando remoção de fôrmas, duração da cura, aplicação de protensão ou de cargas, remoção de escoramento;

$\checkmark$ localização e determinação da extensão de fissuras, vazios e falhas de concretagem;

$\checkmark$ determinação da posição, diâmetro ou condições das armaduras;

$\checkmark$ determinação da uniformidade do concreto;

$\checkmark \quad$ aumento do nível de confiança de um pequeno número de ensaios destrutivos;

$\checkmark$ verificar a deterioração do concreto resultante de sobrecarga, fadiga, fogo, ataque do meio ambiente;

$\checkmark \quad$ avaliação do potencial de durabilidade do concreto;

$\checkmark$ monitoramento de mudanças das propriedades do concreto no decorrer do tempo;

$\checkmark$ fornecimento de informações para mudanças de utilização da estrutura.

O problema é que a deterioração do concreto em estruturas é frequentemente resultado da ação simultânea de vários mecanismos de degradação, que se manifestam em velocidades diferentes e tem distintos efeitos. Estes fatores tornam muito complexas as análises e dependente da expertise de profissionais treinados e capacitados.

Dentre os END utilizados para análise do concreto, o ensaio de Velocidade de Propagação do Pulso Ultrassônico (VPU) pode-se constituir uma estratégia interessante para monitorar o estado de conservação das estruturas de concreto. $\mathrm{O}$ presente artigo evidencia como podem ser empregados os ensaios de VPU para controle de estruturas.

\section{APLICAÇÃO DO ENSAIO ULTRASSÔNICO NO CONCRETO}

Em decorrência do fato de o concreto ser o material mais utilizado na construção civil justifica a realização de estudos sobre os fatores que podem afetar suas propriedades e sobre as formas de medir as mesmas. A resistência à compressão é a propriedade de controle mais empregada para analisar a qualidade deste material. Parte-se do princípio que se um concreto não é suficientemente resistente, pode não suportar as cargas de projeto ou a ação dos agentes ambientais, resultando em danos que podem ser caros de corrigir, numa vida de serviço encurtada ou no desmoronamento da estrutura edificada.

Levando-se em conta que a resistência está fortemente correlacionada com a densidade do material, pode-se utilizar o ensaio de VPU para estimar a mesma, sem que seja necessário retirar amostras do material. Esta possibilidade é muito atraente, pois evita que a investigação da resistência provoque danos no material, ou resultem na necessidade de um reparo cuja interface com o material original vai se constituir numa zona mais vulnerável à deterioração, resultando em danos mal corrigidos podem acarretar numa redução da vida de serviço da estrutura. A metodologia do ensaio de VPU está baseada no fato de que o tempo de propagação dos pulsos ultrassônicos expressa a densidade do material.

Segundo a ASTM E 114-95 (1995), o ensaio pode ser utilizado para controle da qualidade, detecção de defeitos, medição de espessuras ou caracterização dos materiais constituintes do concreto. A presença de vazios causa o retardo das ondas, em função da baixa velocidade do som no ar. A interpretação está, portanto, baseada no fato de que o tempo de propagação dos pulsos ultrassônicos pode ser correlacionado com a densidade do material.

A BSI-1881: Part 201(1986) considera que as principais aplicações deste método são:

$\checkmark$ determinação da uniformidade do concreto; 
determinação da existência de fissuras;

$\checkmark$ estimativa da resistência à compressão do concreto, utilizando para tal curvas de correlação apropriadas;

$\checkmark$ monitoramento da evolução da resistência;

$\checkmark$ avaliação da deterioração do concreto.

Uma das vantagens é que, por ser rápido e não-destrutivo, os ensaios de VPU oferece a oportunidade de fazer um controle total dos elementos que compõem a estrutura, inclusive ao longo do tempo. Os resultados deste tipo de análise podem ser usados para prognóstico da qualidade ou para correção do processo tecnológico. A Figura 1 ilustra a execução do ensaio de VPU.

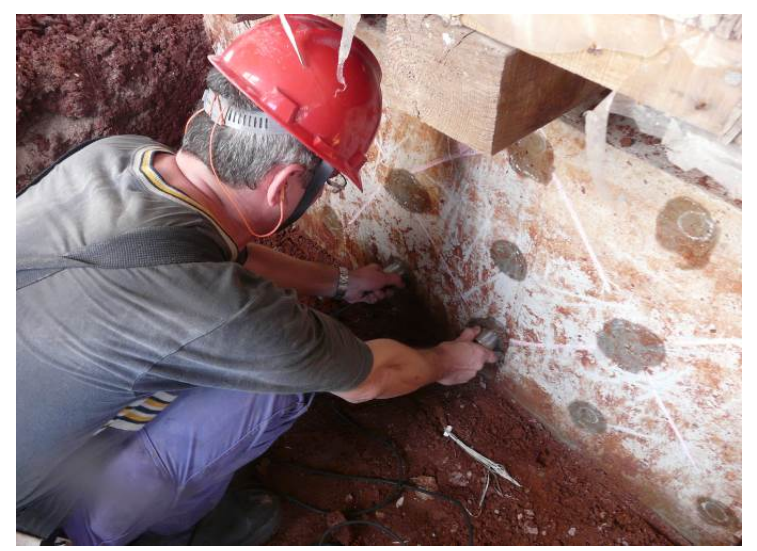

Figura 1: Execução do Ensaio de VPU

Um grande número de variáveis, potencialmente, afeta a correlação de resultados de compacidade, obtidos via pulso ultrassônico, e de resistência à compressão do concreto. A relação água-cimento $(\mathrm{a} / \mathrm{c}), \mathrm{o}$ tamanho do agregado, o teor de umidade, a técnica de moldagem, o tamanho das amostras e o tipo de cimento, por exemplo, afetam diretamente a resistência à compressão. A eficiência da técnica desta forma é limitada, sendo mais útil para estudos comparativos da resistência ao longo do tempo ou de mapeamento de variações de resistência numa estrutura.

\section{METODOLOGIA}

A técnica de mapeamento da VPU através da transmissão indireta tem sido amplamente utilizada, com grande sucesso, pela equipe do LEME/UFRGS para esse tipo de análise, devido à sua facilidade de execução, excelente capacidade de detecção de falhas e rapidez, fatores estes que permitem efetuar uma varredura completa e adequada do concreto. A propagação dos pulsos ultrassônicos em um material é muito sensível à presença de falhas, fissuras ou qualquer outra descontinuidade no material. Para a realização das medições de VPU nas estruturas de concreto ensaiadas, foram criados grids nas faces das referidas estruturas, com espaçamento de $25 \mathrm{~cm}$ (Figura 2). Foram estabelecidos uma série de pontos, denominados de E1 e E2, para posicionamento do transdutor emissor. Enquanto o emissor era mantido no ponto E1, o receptor era posicionado nas posições em torno do mesmo, resultando em 8 leituras de tempo de propagação de pulso. $\mathrm{O}$ emissor era então mudado para o ponto E2, onde se repetia este procedimento.

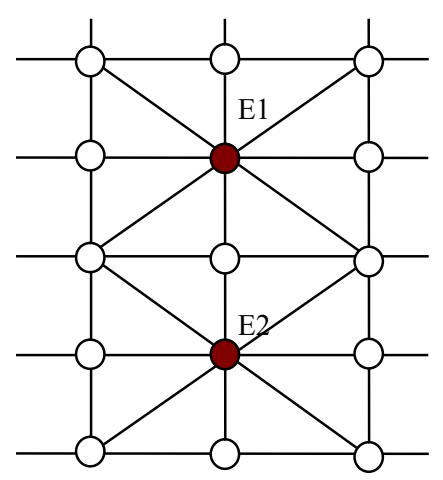

Figura 2: Grid de medição para leituras ultrassônicas. 
As variações da VPU foram mapeadas graficamente através da utilização de um programa computacional apropriado que possibilitava a geração de curvas de nível, facilitando a visualização das variações na homogeneidade, compacidade e integridade de cada elemento. A Figura 3 ilustra a escala de cores empregada pelo programa para a realização das imagens das estruturas ensaiadas.

O objetivo principal é mapear a homogeneidade do concreto dos elementos de interesse, coletando dados que permitissem avaliar comparativamente as características dos mesmos. A partir da análise dos resultados obtidos nos ensaios pode-se mapear as estruturas para definir estratégias de recuperação dos elementos.

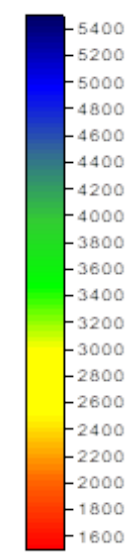

Figura 3: Escala de cores empregadas para as velocidades de propagação da onda ultrassônica na análise dos elementos examinados.

\section{APLICAÇÃO PRATICA}

A aplicação pratica ilustra uma série de aplicações dos ensaios de VPU para avaliar a qualidade das estruturas de concreto. Esses elementos foram estruturas de concreto de uma barragem de grande porte, aonde o controle de qualidade gerou duvidas a respeito do estado do concreto na estrutura e foram determinados pelo agente fiscalizador da obra civil.

\subsection{Estudo de Caso 1}

Este estudo de caso foi realizado em um pilar parede de uma barragem com dimensões de $12 \times 36$ metros e envolveu a determinação da VPU entre pontos localizados em uma malha de medição criada sobre as superfícies das estruturas sob análise. O mapeamento gráfico foi realizado a partir do processamento das leituras obtidas através da utilização de um GRID de medida que variava conforme o tamanho da estrutura analisada.

Os resultados obtidos no mapeamento da estrutura indicaram a existência de uma grande quantidade de vazios e descontinuidades. O mapeamento da VPU nesta estrutura indicou várias regiões com valores abaixo de $2000 \mathrm{~m} / \mathrm{s}$, indicando a necessidade de uma intervenção na estrutura. Neste estudo de caso foi utilizada uma escala de cores diferente em virtude que necessitavam saber as regiões suspeitas da estrutura. A partir de análises prévias, definiu-se que o valor minimo seria $2000 \mathrm{~m} / \mathrm{s}$. A Figura 4 mostra a distribuição de velocidades na estrutura. Uma posterior extração de testemunhos indicou a existência de um grande número de vazios.

Após a análise das imagens geradas foi feito um levantamento de forma a identificar os pontos da estrutura em que se tinha duvidas a respeito da qualidade do concreto. Nos pontos em questao realizou-se a extração de testemunhos para avaliar se o mapeamento grafico do pilar seria suficiente para determinar quais os pontos da estrutura deveriam ser reparados. A aplicação desta metodologia permitiu uma grande redução monetária na recuperação da estrutura. A figura 5 apresenta os resultados do exame visual efetuado em testemunhos extraídos de regiões marcadas por diferentes valores de VPU. A análise dos mesmos permite aperfeiçoar o diagnóstico, definindo qual a faixa de resultados que corresponderia à presença de vazios inaceitáveis na estrutura. 

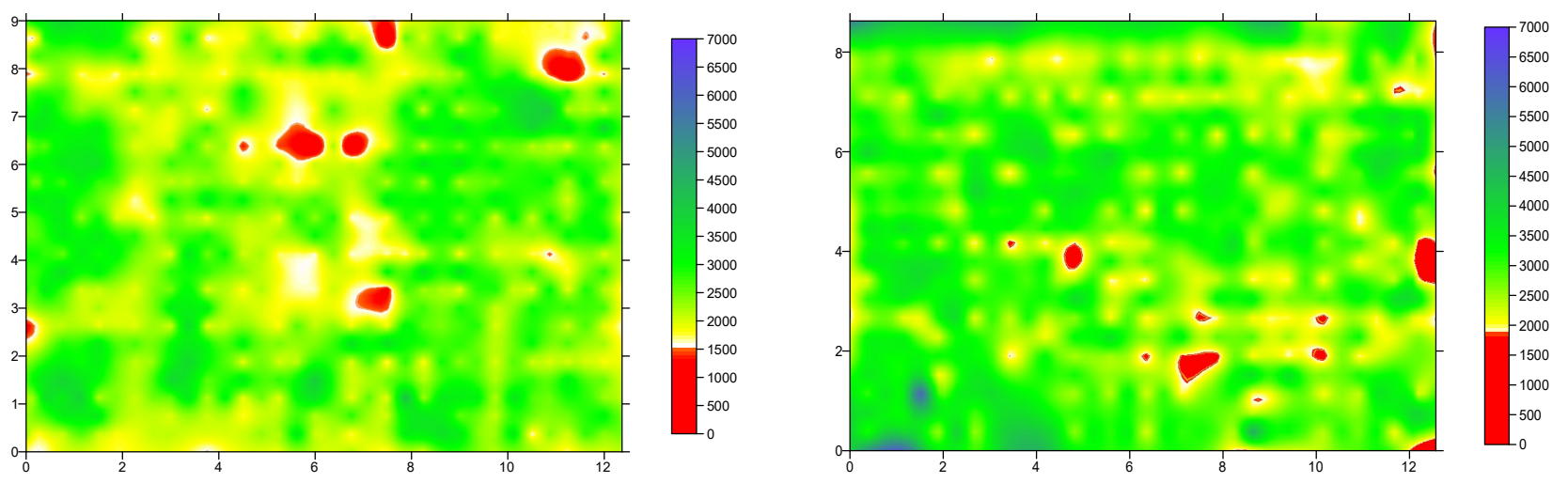

Figura 4: Mapeamento da VPU da estrutura em análise.
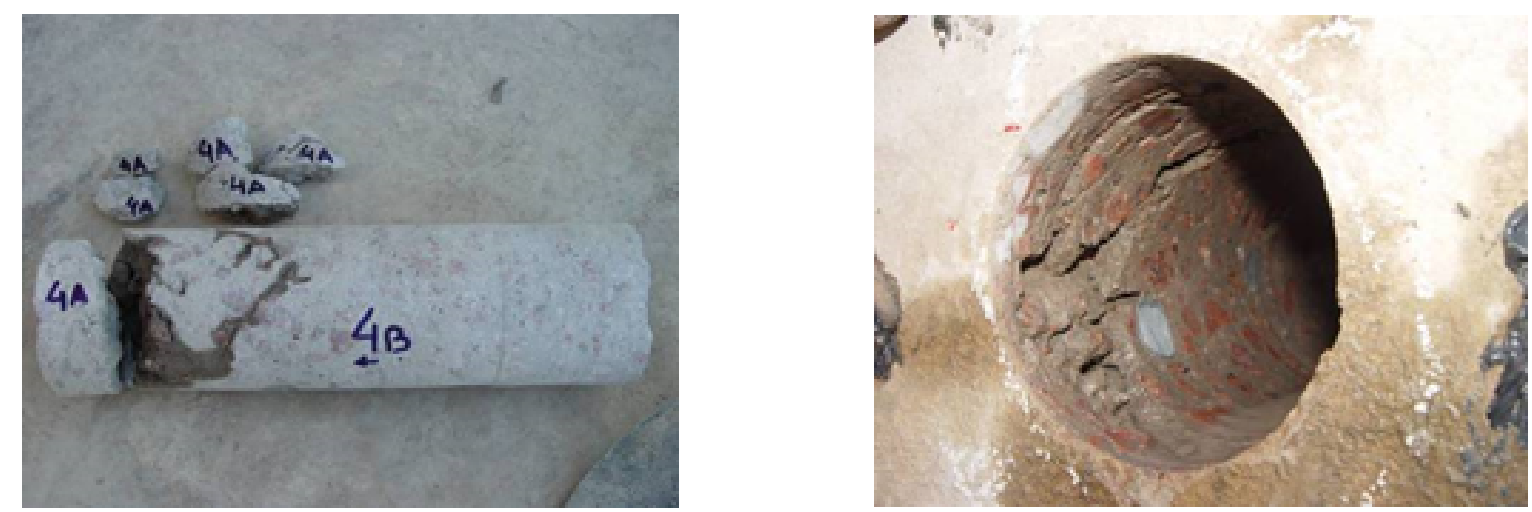

Figura 5: Exame visual de testemunhos extraídos da estrutura.

\subsection{Estudo de Caso 2}

Verifica-se, através da análise dos resultados obtidos no ensaio qualitativo do concreto via ultrassonografia, que as leituras obtidas indicam a existência de zonas de concreto com características distintas na estrutura examinada. Em alguns trechos foram registradas velocidades de propagação de onda mais elevadas do que em outros.

A partir da análise do projetos, observou-se uma certa correspondência entre estas zonas e o esquema de concretagem utilizado, com zonas mais propensas a vazios e falhas de concretagem devido à densidade elevada da ferragem. A Figura 6 apresenta as imagens geradas com as leituras de VPU de alguns dos pilares analisados. As velocidades registradas variaram entre 2400 e $3200 \mathrm{~m} / \mathrm{s}$. Em geral o concreto apresenta uma qualidade regular, com registros de zonas mais compactas na parte inferior e zonas menos compactas na parte superior dos pilares, como esperado.

Em todos os pilares se observam algumas regiões, distribuídas principalmente nas extremidades superiores dos pilares, onde a velocidade cai, evidenciando a existência de pequenos defeitos ou variações na compacidade do material, típicas de estruturas confeccionadas com um material heterogêneo como o concreto. 


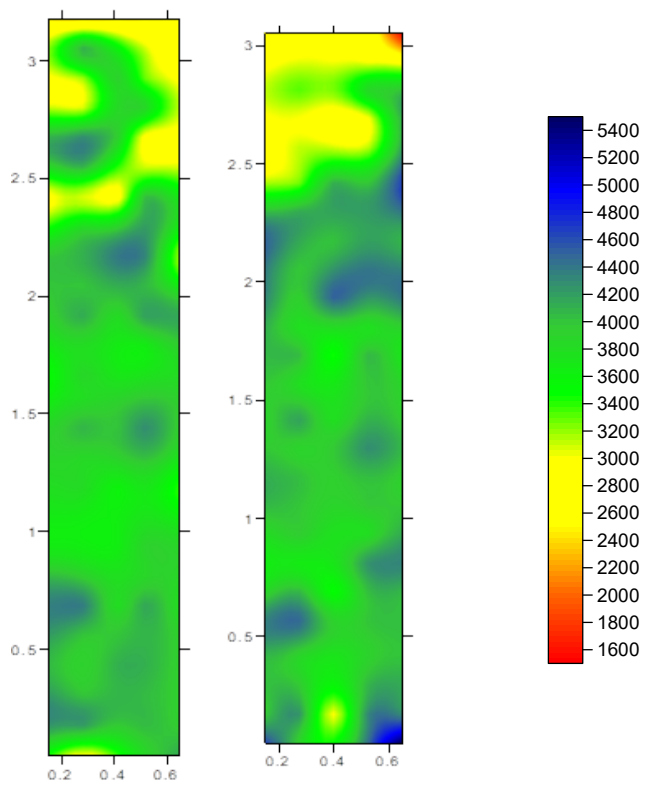

Figura 6: Mapeamento do ensaio de VPU para alguns dos pilares ensaiados.

\subsection{Estudo de Caso 3}

A Figura 7 apresenta imagem gerada com as leituras de VPU de blocos de fundação. As velocidades registradas variaram entre 2400 e $2800 \mathrm{~m} / \mathrm{s}$. Os resultados do mapeamento das leituras de VPU permitiram identificar que existem diferenças nas características dos concretos empregados. Considerando os resultados obtidos pode-se afirmar que a hipótese de que os concretos de todos os elementos analisados apresentam características similares não pode ser aceita.

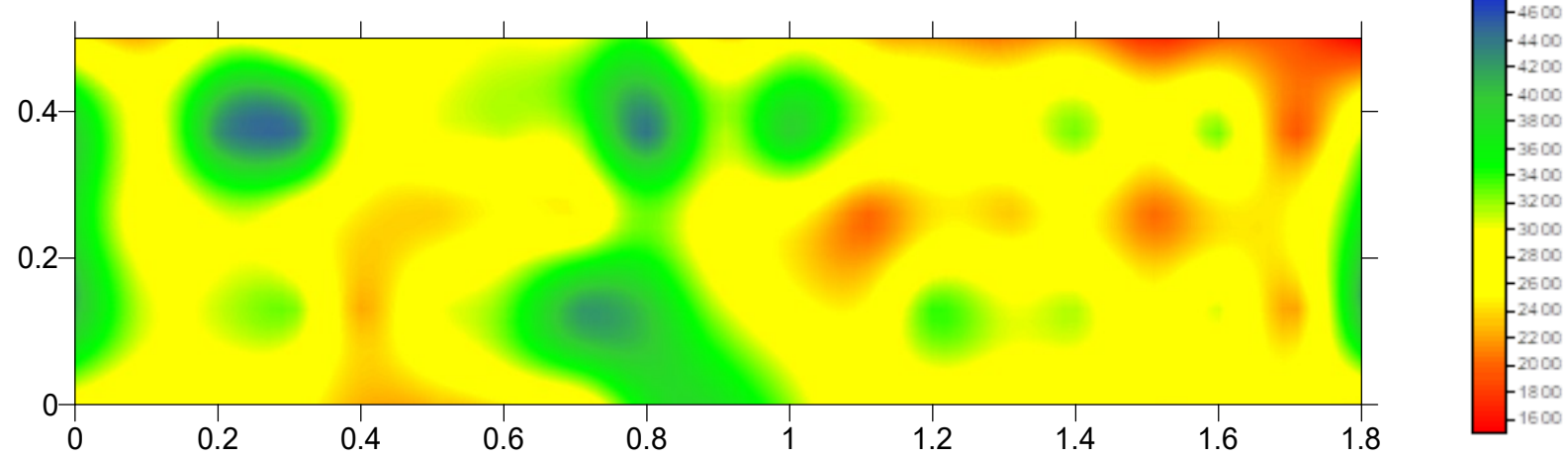

Figura 7: Resultados do mapeamento dos dados do ensaio de pulso ultrassônico.

\section{CONCLUSÕES}

A falta de informação, numa situação de caráter emergencial, pode fazer com que se tomem decisões conservadoras, aumentando o escopo e complexidade das intervenções previstas, aumentando custos ou gerando transtornos adicionais para seus usuários.

A utilização de ensaios de VPU poderá ser uma ferramenta auxiliar na tomada de decisão e estabelecimento de estratégias de intervenção, como demonstrado nos estudos de caso descrito no presente artigo. A investigação a respeito da condição do concreto nas estruturas evidenciou claramente a potencialidade de ensaios tipo VPU para checagem das 
condições de estrutura de concreto. A análise dos dados de VPU provêem informações sobre o concreto, indicando a posição de falhas e de vazios, com uma estimativa de seu tamanho.

O estudo indica que ensaios de VPU são sensíveis a variações de homogeneidade e densidade, podendo, portanto, fornecer dados importantes para a tomada de decisão a respeito das condições de estruturas de concreto. Ou seja, podese concluir que, mediante a execução de ensaios de VPU é possível contribuir com o controle da qualidade das estruturas de concreto. Toda a análise deve ser feita com muito cuidade e levar em conta que outros fatores poderao influenciar nos resultados obtidos. Em todas as situacoes que for possivel extrair testemunhos para validar a análise por VPU esta deve ser o procedimento a ser executado.

De forma geral, os estudos de caso apresentados no presente artigo reforçam a idéia de que a utilização de VPU vem a ser uma ferramenta útil para a análise de estruturas. A partir dos referidos ensaios permite-se a verificação da qualidade e compacidade das estruturas de concreto. Confirma-se assim a premissa de que o ensaio de VPU têm grande potencial de utilização nos casos de inspeção de estruturas. Seu emprego permite obter indicações importantes para a caracterização do concreto, bem como dados sobre a homogeneidade e a qualidade da estrutura.

\section{REFERÊNCIAS}

ANNUAL BOOK OF ASTM STANDARDS. ASTM E 114-95, Standard Practice for Ultrasonic Pulse-Echo Straight-Beam Examination by the Contact Method, Vol. 03.03 Nondestructive Testing, West Conshohocken, USA: ASTM, 920 pp. 12-15, 1995.

BALAYSSAC, J. P. et al., Evaluation of concrete structures by combining non-destructive testing methods (SENSO project). In: Non-Destructive Testing in Civil Engineering (NDTCE 2009), Nantes. Proceedings.... Paris: Confédération Française pour les Essais Non Destructifs, 2009.

BRITISH STANDARDS INSTITUTION. BSI 1881 - Part 203: Recommendations for measurement of velocity of ultrasonic pulses in concrete, London: 1986. 20 p.

INTERNATIONAL ATOMIC ENERGY AGENCY. IAEA-TCS-17: Guidebook on Non-Destructive Testing of Concrete Structures. Viena: 2002, 231 p. 